\title{
Combined Multichannel Intraluminal Impedance and High-resolution Manometry Improves Detection of Clinically Relevant Esophagogastric Junction Outflow Obstruction
}

\author{
Byeong Geun Song, Yang Won Min, Hyuk Lee, Byung-Hoon Min, Jun Haeng Lee, Poong-Lyul Rhee, ${ }^{*}$ and Jae J Kim \\ Department of Medicine, Samsung Medical Center, Sungkyunkwan University School of Medicine, Seoul, Korea
}

\begin{abstract}
Background/Aims
Esophagogastric junction outflow obstruction (EGJOO) is a diagnostically heterogeneous group with variable clinical relevance. We studied whether evaluation of bolus transit by multichannel intraluminal impedance (MII) is useful for discriminating clinically relevant EGJOO.

Methods

A total 169 patients diagnosed as having EGJOO between June 2011 and February 2018 were analyzed. All the patients received a combined MII and high-resolution manometry (CMII-HRM). MII was reported as having abnormal liquid bolus transit (LBT) if $<80 \%$ of swallows had complete bolus transit. EGJOO was defined as a median integrated relaxation pressure of $>20 \mathrm{mmHg}$ and when the criteria for achalasia were not met. Patients who progress to achalasia, show significant passage disturbance, or require pneumatic dilatation were defined as having a clinically relevant EGJOO.

Results

Among the patients with EGJOO $(n=169)$, the clinically relevant group $(n=10)$ is more likely to have dysphagia $(100 \%$ vs $25.2 \%$, $P<0.001)$, compartmentalized pressurization $(C P ; 90.0 \%$ vs $22.0 \%, P<0.001)$, and abnormal LBT $(100 \%$ vs $66.7 \%, P=0.032)$ compared to the non-relevant group $(n=159)$. The combination of dysphagia, $C P$, and abnormal LBT showed the best predictive power for clinically relevant EGJOO (sensitivity $90 \%$, specificity $92.5 \%$, positive predictive value $42.9 \%$, negative predictive value $99.3 \%$, positive likelihood ratio 11.9 , and negative likelihood ratio 0.1 ). When CMII-HRM was used, an additional $8.3 \%$ of clinically relevant EGJOO cases were identified as compared with HRM alone.
\end{abstract}

Conclusion

Clinically relevant EGJOO can be predicted using CMII-HRM.

(J Neurogastroenterol Motil 2019;25:75-81)

Key Words

Electric impedance; Esophageal achalasia; Esophagogastric junction; Manometry

Received: September 6, 2018 Revised: October 5, 2018 Accepted: October 25, 2018

(.) This is an Open Access article distributed under the terms of the Creative Commons Attribution Non-Commercial License (http://creativecommons. org/licenses/by-nc/4.0) which permits unrestricted non-commercial use, distribution, and reproduction in any medium, provided the original work is properly cited.

${ }^{*}$ Correspondence: Poong-Lyul Rhee, MD, PhD

Department of Medicine, Samsung Medical Center, Sungkyunkwan University School of Medicine, 81 Irwon-ro, Gangnam-gu, Seoul 06351, Korea

Tel: +82-2-3410-3409, Fax: +82-2-3410-6983, E-mail: pl.rhee@samsung.com

Byeong Geun Song and Yang Won Min contributed equally to this work. 


\section{Introduction}

Esophagogastric junction outflow obstruction (EGJOO) is a clinically heterogenous manometric diagnosis. ${ }^{1,2}$ It is non-uniform diagnostic group and is considered a group of multiple clinical subsets. Additional tests such as barium esophagography, esophagogastroduodenoscopy, and endoscopic ultrasonography are needed because some patients have a structural cause of elevated integrated relaxation pressure (IRP). ${ }^{1-5}$ However, most patients with EGJOO do not have a definite cause of IRP elevation. ${ }^{4}$ In some patients, idiopathic EGJOO progresses to achalasia, and these patients show significant dysphagia and/or passage disturbance. ${ }^{6-8}$ However, in a significant number of patients, elevated IRP is a coincidental finding without any clinical relevance. ${ }^{2,6}$ Recently, several studies have clearly shown that dysphagia and compartmentalized pressurization (CP) is closely related to clinically significant idiopathic EGJOO., ${ }^{4,9}$ In real practice, prediction of the clinical relevance of EGJOO is of great importance because of its diagnostic heterogeneity.

Multichannel intraluminal impedance (MII) of esophageal function was first described by Silny et $\mathrm{al}^{10}$ in 1991. Impedance test allows detection and quantification of bolus movement by measuring differences in resistance to alternating current of the intraluminal contents. ${ }^{11-13}$ Several studies that used combined videofluoroscopy and impedance validated the ability of impedance to evaluate bolus transit. ${ }^{14,15}$ The combined use of MII and highresolution manometry (CMII-HRM) was reported to provide useful information about esophageal motility abnormality and the functional detail of bolus transit more precisely. ${ }^{12,16-19}$ In addition to clinicomanometric variables, bolus transit measured using MII, a parameter of the functional aspect of the esophageal contraction, may provide additional clinical information in patients diagnosed as having EGJOO on HRM. ${ }^{16}$

Our study aims to investigate whether evaluation of bolus transit by using MII is useful for discriminating clinically relevant EGJOO.

\section{Materials and Methods}

\section{Subjects}

The data of patients who received CMII-HRM between June 2011 and February 2018 were reviewed. EGJOO was defined when median IRP was elevated ( $>20 \mathrm{mmHg}$ ) without meeting the criteria of achalasia according to the Chicago classification. ${ }^{5}$
Median IRP $20 \mathrm{mmHg}$ was adopted as cutoff for diagnosing EGJOO in Sandhill HRM with reference to previous studies. ${ }^{9,20-22}$ As a result, a total of 169 patients with EGJOO were included in the analysis. Clinically relevant patients were defined as follows: (1) subsequent HRM met achalasia criteria during follow-up (early achalasia); (2) Eckardt score was decreased at least two points without exceeding a score of 3 after pneumatic dilatation (variant achalasia); or (3) significant passage disturbance on esophagogram without structural abnormality (possible achalasia). ${ }^{9}$ The study was performed in accordance with the ethical guidelines of the Declaration of Helsinki and approved by the institutional review board at Samsung Medical Center (IRB No. 2018-03-101). Since the study was based on the retrospective analysis of existing administrative and clinical data, the requirement of obtaining informed consent was waived by the institutional review board.

\section{Multichannel Intraluminal Impedance and Esophageal Manometry}

CMII-HRM was conducted by using a high-resolution impedance manometry system (Sandhill Scientific, Inc, Highlands Ranch, CO, USA). Manometric and Impedance data were analyzed automatically using BioView Analysis (Sandhill Scientific) software, and then each study was blindly reviewed manually. The probe had 32 circumferential pressure sensors spaced $1 \mathrm{~cm}$ apart and 16 impedance channels with a $2-\mathrm{cm}$ spacing. CMII-HRM was conducted in standard fashion with a series of 10 swallows of $5-\mathrm{mL}$ normal saline with the subject in the supine position. Bolus entry was defined as a $>50 \%$ drop in impedance level from the baseline at the proximal recording site, and complete bolus transit (CBT) was defined as a $>50 \%$ drop from the baseline followed by an increase of at least $50 \%$ towards the original baseline at the 3 distal impedance recording sites after bolus entry. ${ }^{23} \mathrm{MII}$ findings were reported as having normal bolus transit if $\geq 80 \%$ of liquid swallows had CBT. ${ }^{16,24,25}$

HRM metrics were established based on the Chicago classification version 3.0. ${ }^{5}$ The contraction amplitude of the esophageal body was assessed with the distal contractile integral (DCI), and the propagation of contractions along the esophageal body was assessed with distal latency (DL). CP was defined when pressurization was $>30 \mathrm{mmHg}$, extending from the contractile front to the esophagogastric junction (EGJ), in at least one swallow during the study. EGJ subtypes were defined as follows: (1) type I EGJ subtype: complete overlap of crural diaphragm and lower esophageal sphincter (LES) components with single peak on the spatial pressure variation plot; (2) type II EGJ subtype: double-peaked pressure zone 
with the interpeak nadir pressure greater than gastric pressure and a separation of 1-2 cm between peaks; and (3) type III EGJ subtype: double-peaked pressure zone with the interpeak nadir pressure.

\section{Statistical Methods}

Data are expressed as the mean \pm standard deviation, median (range), or $\mathrm{n}(\%)$ as appropriate. Clinicomanometric characteristics were compared between the patients with clinically relevant EGJOO and those with non-clinically relevant EGJOO. Differences among the continuous and categorical variables were examined for statistical significance using the Student's $t$ test (or Mann-Whitney $U$ test, if appropriate) and chi-square test (or Fisher's exact test, if appropriate), respectively. A $P$-value of less than 0.05 with a twotailed test was considered significant. All statistical analyses were performed using SPSS version 24.0 (IBM Corp, Armonk, NY, USA).

\section{Results}

\section{Baseline Characteristics}

The clinicomanometric baseline characteristics of the patients are summarized in Table 1. A total of 169 patients were included in the analysis. The mean age of the patients was $56 \pm 12$ years, and the proportion of males was $30.2 \%(\mathrm{n}=51)$. The mean followup duration was $26.2 \pm 24.4$ months. The mean IRP was 24.0
mmHg (range, 20.0-74.0 mmHg), and no statistically significant difference in IRP was found between the clinically relevant and non-clinically relevant groups (25.5 vs $24.0 \mathrm{mmHg}, P=0.122$ ). In addition, other manometric variables did not differ between the 2 groups.

\section{Predictors Associated With Clinically Relevant Esophagogastric Junction Outflow Obstruction}

Among the 169 patients with EGJOO, 10 were clinically relevant, whereas 159 were not (Fig. 1). Dysphagia (100\% vs $25.2 \%$, $P<0.001)$, CP (90.0\% vs $22.0 \%, P<0.001)$, and abnormal liquid bolus transit (LBT; $100 \%$ vs $66.7 \%, P=0.032$ ) were more common in the clinically relevant group than in the non-clinically relevant group. However, age, sex, follow-up duration, EGJ subtype, IRP, DCI, and DL did not differ significantly between the 2 groups (Table 1).

\section{Prediction of Clinically Relevant Esophagogastric Junction Outflow Obstruction}

The proportions of patients with clinically relevant EGJOO who only had dysphagia, CP, or abnormal LBT were $20.0 \%$, $20.5 \%$, and $8.6 \%$, respectively. Of the patients with two predictors (CP with dysphagia, CP with abnormal LBT, and dysphagia with abnormal LBT), $34.6 \%, 25.0 \%$, and $25.0 \%$ had clinically relevant EGJOO, respectively. Notably, among the patients who had all 3 predictors, $42.9 \%$ were clinically relevant (Table 2 and Fig. 2). The

Table 1. Comparison of Clinicomanometric and Impedance Variables between Clinically Relevant and Non-clinically Relevant Esophagogastric Junction Outflow Obstructions

\begin{tabular}{|c|c|c|c|c|}
\hline Variables & Total $(\mathrm{n}=169)$ & Relevant $(\mathrm{n}=10)$ & Non-relevant $(\mathrm{n}=159)$ & $P$-value \\
\hline Age (yr) & $56 \pm 12$ & $59 \pm 9$ & $55 \pm 12$ & 0.297 \\
\hline Male & $51(30.2)$ & $4(40.0)$ & $47(29.6)$ & 0.491 \\
\hline Follow-up (mo) & $26.2 \pm 24.4$ & $11.2 \pm 23.7$ & $27.2 \pm 24.2$ & 0.071 \\
\hline Dysphagia as chief complaint & $50(29.6)$ & $10(100)$ & $40(25.2)$ & $<0.001$ \\
\hline \multicolumn{5}{|l|}{ Manometric variables } \\
\hline EGJ subtype & & & & 0.852 \\
\hline Type I & $131(77.5)$ & $8(80.0)$ & $123(77.4)$ & \\
\hline Type II & $25(14.8)$ & $1(10.0)$ & $24(15.1)$ & \\
\hline Type III & $13(7.7)$ & $1(10.0)$ & $12(7.5)$ & \\
\hline $\operatorname{IRP}(\mathrm{mmHg})$ & $24.0(20.0-74.0)$ & $25.5(20.0-50.0)$ & $24.0(20.0-74.0)$ & 0.122 \\
\hline DCI (mmHg·sec $\cdot c m)$ & $2155.4 \pm 2172.5$ & $3514.3 \pm 5888.6$ & $2070.0 \pm 1708.5$ & 0.459 \\
\hline $\mathrm{DL}(\mathrm{sec})$ & $6.4(0.0-12.9)$ & $6.2(1.0-10.0)$ & $6.4(0.0-12.9)$ & 0.788 \\
\hline Compartmentalized pressurization & $44(26.0)$ & $9(90.0)$ & $35(22.0)$ & $<0.001$ \\
\hline$\%$ LBT & $50(0-100)$ & $0(0-50)$ & $60(0-100)$ & $<0.001$ \\
\hline Abnormal LBT & $116(68.6)$ & $10(100)$ & $106(66.7)$ & 0.032 \\
\hline
\end{tabular}

EGJ, esophagogastric junction; IRP, integrated relaxation pressure; DCI, distal contractile integral; DL, distal latency; LBT, liquid bolus transit.

Data are expressed as the mean $\pm \mathrm{SD}, \mathrm{n}(\%)$, or median (range). 

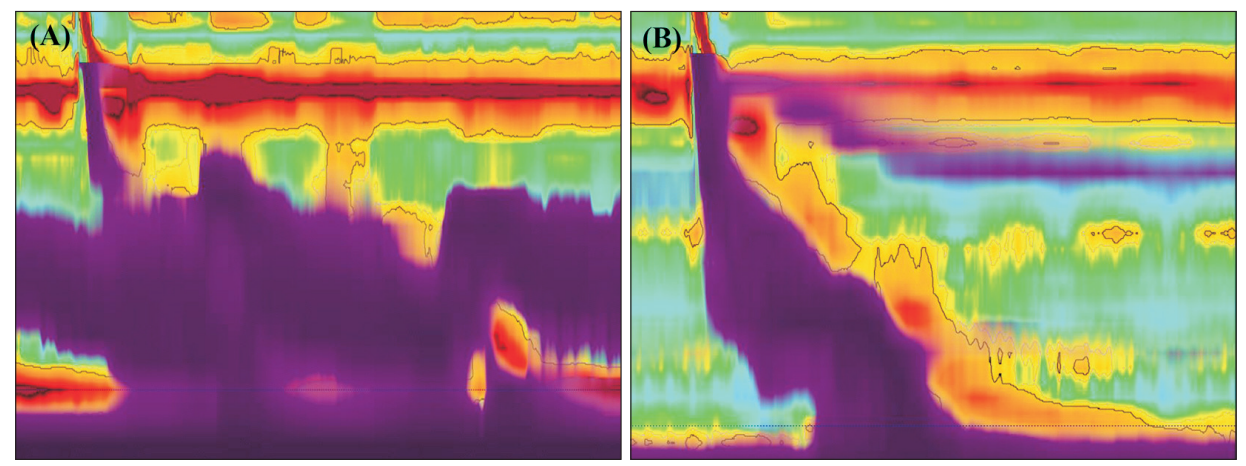

Figure 1. Improved esophageal bolus clearance after peroral endoscopic myotomy (POEM) in a patient with esophagogastric junction outflow obstruction (EGJOO). A 50-year-old woman presented with dysphagia. (A) She was diagnosed as having EGJOO (integrated relaxation pressure, $41 \mathrm{mmHg}$ ) and showed abnormal liquid bolus transit (LBT; 0\%). POEM was performed because no organic cause was found to explain her abnormal dysphagia. (B) After POEM, her symptoms disappeared completely, and the LBT was normalized as indicated by the purple color in the figure.

predictive performance of these predictors for clinically relevant EGJOO was higher when these predictors were combined (Table 3). The combination of all 3 predictors showed the best predictive power for clinically relevant EGJOO (sensitivity 90\%, specificity $92.5 \%$, positive predictive value $42.9 \%$, and negative predictive value $99.3 \%$ ). When we used impedance in addition to dysphagia and $\mathrm{CP}$, we could predict clinically relevant EGJOO more precisely (Fig. 3).

\section{Discussion}

Owing to the unclear clinical significance of EGJOO, it is important to know which variables can identify clinically relevant EGJOO. This study is the first to present predictors that segregate clinically significant EGJOO by combining impedance test with clinicomanometric variables.

The secondary cause of EGJOO includes mechanical obstruction such as esophageal stenosis, infiltrative disease, cancer, and hiatal hernia. ${ }^{1-3,5}$ Thus, it is essential to evaluate the structural cause of IRP elevation. Some patients might evolve to achalasia or have significant dysphagia with passage disturbance requiring intervention. ${ }^{8,26}$ Owing to its diagnostic heterogeneity of EGJOO, it is important to find predictors that can segregate clinically relevant EGJOO.

In a previous study, patients with clinically relevant EGJOO had significantly higher rates of dysphagia (100\% vs $24.3 \%, P<$ $0.001)$ and $\mathrm{CP}(85.7 \%$ vs $21.7 \%, P=0.001)$ than those with nonclinically relevant EGJOO. ${ }^{9}$ Of patients with EGJOO with both dysphagia and CP, $40 \%$ had clinically relevant EGJOO. The pre-
Table 2. Proportions of Clinically Relevant Esophagogastric Junction Outflow Obstruction According to Presence of Dysphagia, Compartmentalized Pressurization, and Liquid Bolus Transit

\begin{tabular}{lc}
\hline \multicolumn{1}{c}{ Predictors } & $\begin{array}{c}\text { Clinically relevant } \\
\text { EGJOO/Patients } \\
\text { having variable(s) }(\%)\end{array}$ \\
\hline Dysphagia & $10 / 50(20.0)$ \\
CP & $9 / 44(20.5)$ \\
Abnormal LBT & $10 / 116(8.6)$ \\
CP + dysphagia & $9 / 26(34.6)$ \\
CP + abnormal LBT & $9 / 36(25.0)$ \\
Dysphagia + abnormal LBT & $10 / 40(25.0)$ \\
Dysphagia + CP + abnormal LBT & $9 / 21(42.9)$ \\
\hline
\end{tabular}

EGJOO, esophagogastric junction outflow obstruction; CP, compartmentalized pressurization; LBT, liquid bolus transit.

dictive performance was a little disappointing. Moreover, there was no evaluation items for functional aspects that were expected to be important in predicting clinical significance. This study was performed to overcome these limitations. In effect, MII, which is used to evaluate the functional aspect of esophageal contraction, demonstrated its effectiveness in several studies. ${ }^{18,27,28}$ In the present study, an objective dysfunctional result, which is abnormal bolus transit, was also a statistically significant factor for segregating clinically relevant EGJOO. Our study showed that patients who had all 3 predictors are more likely to have clinical significance (Fig. 2). This multidimensional approach, including symptom, manometric finding, and impedance test, would improve the reliability of EGJOO diagnosis.

Zheng et $\mathrm{al}^{29}$ reported that EGJOO is associated with often 
coexistent abnormal bolus transit. In addition, a study by Jain et $\mathrm{al}^{23}$ reported that bolus transit is impaired in EGJOO, but not as severely as in achalasia. These studies clearly showed the association between abnormal bolus transit and EGJOO. The role of CMIIHRM for early diagnosis of achalasia or in the evaluation of potential progress of EGJOO to achalasia (early achalasia) was studied, with promising results. ${ }^{30}$ In addition, Tutuian and Castell ${ }^{18}$ reported that none of the patients with achalasia and scleroderma had normal bolus transit, whereas almost all patients with normal esophageal manometry, nutcracker esophagus, poorly relaxing LES, hypertensive LES, and hypotensive LES had normal bolus transit. These studies consistently suggested that patients with clinically relevant EGJOO tend to have abnormal bolus transit. Thus, we can infer that bolus transit measured using an impedance test might be a significant variable for differentiating between clinically relevant

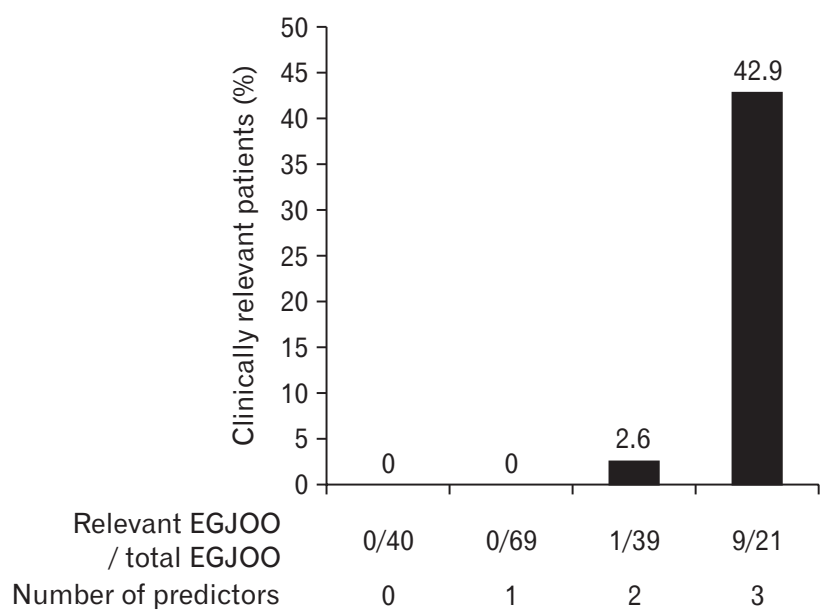

Figure 2. Prediction of clinical relevance of esophagogastric junction outflow obstruction (EGJOO) according to the number of predictors. ${ }^{*} P<0.001$ vs predictors 0,1 , or 2 , each.
EGJOO and non-clinically relevant EGJOO.

Recently, HRM for the diagnosis of esophageal motility disorders has been widely used, and the diagnostic rate of EGJOO has been increasing. However, no standardized treatment approach has been developed for EGJOO. In most cases, follow-up or sphincter disruption therapy is performed according to the physician's clinical judgment after excluding the structural cause by additional tests such as esophagogastroduodenoscopy, endoscopic ultrasonography, and computed tomography. ${ }^{4}$ According to the present study, approximately $40 \%$ of patients with dysphagia, $\mathrm{CP}$, and abnormal bolus transit were found to have clinically relevant EGJOO. Therefore, patients who had all 3 predictors need to be carefully followed up or considered for sphincter disruption therapy. If these predic-

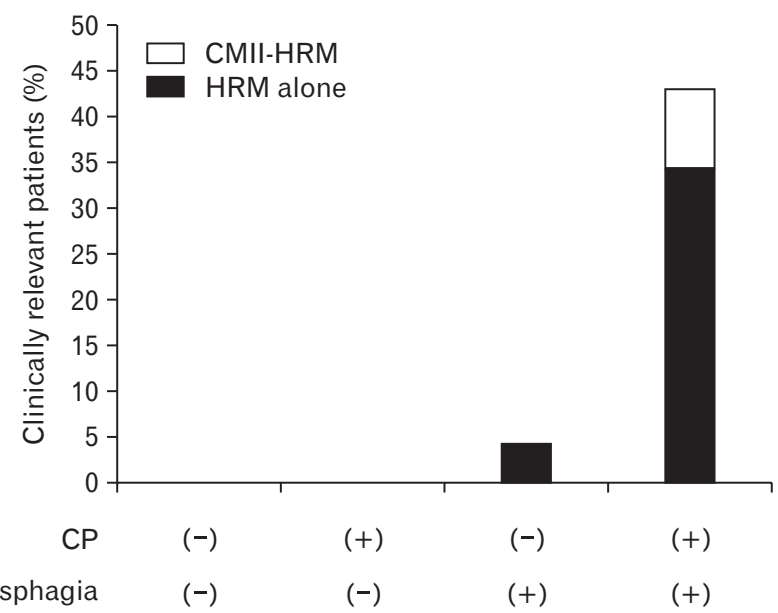

Figure 3. Added value of impedance for prediction of clinically relevant esophagogastric junction outflow obstruction. CP, compartmentalized pressurization; CMII-HRM, combined multichannel intraluminal impedance and high-resolution manometry; HRM, highresolution manometry.

Table 3. Predictive Performance of Dysphagia, Compartmentalized Pressurization, and Liquid Bolus Transit for Clinically Relevant Esophagogastric Junction Outflow Obstruction

\begin{tabular}{lcccccc}
\hline \multicolumn{1}{c}{ Predictors } & Sensitivity $(\%)$ & Specificity $(\%)$ & PPV $(\%)$ & NPV $(\%)$ & LR+ & LR- \\
\hline Dysphagia & 100 & 74.8 & 20.0 & 100 & 4.0 & 0.0 \\
CP & 90.0 & 78.0 & 20.5 & 99.2 & 4.1 & 0.1 \\
LBT & 100 & 33.3 & 8.6 & 100 & 1.5 & 0.0 \\
Dysphagia + CP & 90.0 & 89.3 & 34.5 & 99.3 & 8.4 \\
CP + abnormal LBT & 90 & 83.0 & 25.0 & 99.3 & 5.3 \\
Dysphagia + abnormal LBT & 100 & 81.1 & 25.0 & 100 & 0.1 \\
CP + dysphagia + abnormal LBT & 90 & 92.5 & 42.9 & 99.3 & 0.1 \\
\hline
\end{tabular}

PPV, positive predictive value; NPV, negative predictive value; $\mathrm{LR}+$, positive likelihood ratio; LR-, negative likelihood ratio; CP, compartmentalized pressurization; LBT, liquid bolus transit. 
tors are absent or only 1 or 2 are present, IRP elevation is likely to be a coincidental finding.

Our study has a limitation in that only 10 patients with clinically relevant EGJOO were included. Therefore, the generalization of the results may be limited. Also, this is a retrospective study in a single center. However, this study has novelty by objectively defining clinically relevant EGJOO and finding significant predictors through statistical comparisons. Also, our study has sufficient mean follow-up period of 26 months so we could identify clinically relevant EGJOO more precisely. Furthermore, our study will be useful in clinical practice by presenting specific figures of predictive performance and proportions of clinically relevant EGJOO. Future studies with more patients are needed to identify more variables for predicting clinically relevant EGJOO. Studies involving patient symptoms, HRM parameters, and impedance may help develop an approach for this uncertain diagnostic category.

In conclusion, clinically relevant EGJOO can be predicted using a multidimensional approach that considers the functional aspect of esophageal contraction and clinicomanometric characteristics.

\section{Financial support: None.}

\section{Conflicts of interest: None.}

Author contributions: Byeong Geun Song and Yang Won Min contributed to the data acquisition, data analysis, data interpretation, and manuscript drafting; Hyuk Lee, Byung-Hoon Min, Jun Haeng Lee, and Jae J Kim contributed to data interpretation and manuscript editing; Poong-Lyul Rhee designed and coordinated the study, contributed to the data interpretation, and edited the manuscript; and all the authors approved the final version of the manuscript.

\section{References}

1. Pérez-Fernández MT, Santander C, Marinero A, Burgos-Santamaria D, Chavarria-Herbozo C. Characterization and follow-up of esophagogastric junction outflow obstruction detected by high resolution manometry. Neurogastroenterol Motil 2016;28:116-126.

2. van Hoeij FB, Smout AJ, Bredenoord AJ. Characterization of idiopathic esophagogastric junction outflow obstruction. Neurogastroenterol Motil 2015;27:1310-1316.

3. DeLay K, Austin GL, Menard-Katcher P. Anatomic abnormalities are common potential explanations of manometric esophagogastric junction outflow obstruction. Neurogastroenterol Motil 2016;28:1166-1171.

4. Okeke FC, Raja S, Lynch KL, et al. What is the clinical significance of esophagogastric junction outflow obstruction? evaluation of 60 patients at a tertiary referral center. Neurogastroenterol Motil Published Online First: 9 Apr 2017. doi: 10.1111/nmo.13061.

5. Kahrilas PJ, Bredenoord AJ, Fox M, et al. The Chicago classification of esophageal motility disorders, v3.0. Neurogastroenterol Motil 2015;27:160-174.

6. Scherer JR, Kwiatek MA, Soper NJ, Pandolfino JE, Kahrilas PJ. Functional esophagogastric junction obstruction with intact peristalsis: a heterogeneous syndrome sometimes akin to achalasia. J Gastrointest Surg 2009;13:2219-2225.

7. Schlottmann F, Herbella FA, Patti MG. Understanding the Chicago classification: from tracings to patients. J Neurogastroenterol Motil 2017;23:487-494.

8. Shin IS, Min YW, Rhee PL. Esophagogastric junction outflow obstruction transformed to type II achalasia. J Neurogastroenterol Motil 2016;22:344-345.

9. Song BG, Min YW, Lee H, et al. Clinicomanometric factors associated with clinically relevant esophagogastric junction outflow obstruction from the Sandhill high-resolution manometry system. Neurogastroenterol Motil Published Online First: 10 Oct 2018. doi: 10.1111/nmo.13221.

10. Silny J. Intraluminal multiple electric impedance procedure for measurement of gastrointestinal motility. Neurogastroenterol Motil 1991;3:151162.

11. Nguyen HN, Silny J, Matern S. Multiple intraluminal electrical impedancometry for recording of upper gastrointestinal motility: current results and further implications. Am J Gastroenterol 1999;94:306-317.

12. Tutuian R. Evaluating esophageal bolus transit by impedance monitoring. Gastrointest Endosc Clin N Am 2014;24:595-605.

13. Bogte A, Bredenoord AJ, Oors J, Siersema PD, Smout AJ. Assessment of bolus transit with intraluminal impedance measurement in patients with esophageal motility disorders. Neurogastroenterol Motil 2015;27:14461452.

14. Silny J, Knigge KP, Fass J, Rau G, Matern S, Schumpelick V. Verification of the intraluminal multiple electrical impedance measurement for the recording of gastrointestinal motility. Neurogastroenterol Motil 1993;5:107-122.

15. Simrén M, Silny J, Holloway R, Tack J, Janssens J, Sifrim D. Relevance of ineffective oesophageal motility during oesophageal acid clearance. Gut 2003;52:784-790.

16. Savarino E, Tutuian R. Combined multichannel intraluminal impedance and manometry testing. Dig Liver Dis 2008;40:167-173.

17. Pandolfino JE, Bulsiewicz WJ. Evaluation of esophageal motor disorders in the era of high-resolution manometry and intraluminal impedance. Curr Gastroenterol Rep 2009;11:182-189.

18. Tutuian R, Castell DO. Combined multichannel intraluminal impedance and manometry clarifies esophageal function abnormalities: study in 350 patients. Am J Gastroenterol 2004;99:1011-1019.

19. Burgess NG, Wyeth JW. An audit of combined multichannel intraluminal impedance manometry in the assessment of dysphagia. J Gastroenterol Hepatol 2011;26(suppl 3):79-82.

20. do Carmo GC, Jafari J, Sifrim D, de Oliveira RB. Normal esophageal pressure topography metrics for data derived from the Sandhill-Unisen- 
sor high-resolution manometry assembly in supine and sitting positions. Neurogastroenterol Motil 2015;27:285-292.

21. Gao F, Gao Y, Hobson AR, Huang WN, Shang ZM. Normal esophageal high-resolution manometry and impedance values in the supine and sitting positions in the population of Northern China. Dis Esophagus 2016;29:267-272.

22. Shi Y, Xiao Y, Peng S, Lin J, Xiong L, Chen M. Normative data of high-resolution impedance manometry in the Chinese population. J Gastroenterol Hepatol 2013;28:1611-1615.

23. Jain A, Baker JR, Rubenstein JH, Chen JW. Bolus clearance in esophagogastric junction outflow obstruction is associated with strength of peristalsis. Neurogastroenterol Motil Published Online First: 3 May 2017. doi: 10.1111/nmo.13093.

24. Tutuian R, Vela MF, Balaji NS, et al. Esophageal function testing with combined multichannel intraluminal impedance and manometry: multicenter study in healthy volunteers. Clin Gastroenterol Hepatol 2003;1:174-182.

25. Nguyen NQ, Rigda R, Tippett M, Conchillo J, Smout AJ, Holloway $\mathrm{RH}$. Assessment of oesophageal motor function using combined perfu- sion manometry and multi-channel intra-luminal impedance measurement in normal subjects. Neurogastroenterol Motil 2005;17:458-465.

26. van Hoeij FB, Bredenoord AJ. Clinical application of esophageal highresolution manometry in the diagnosis of esophageal motility disorders. J Neurogastroenterol Motil 2016;22:6-13.

27. Tutuian R, Castell DO. Clarification of the esophageal function defect in patients with manometric ineffective esophageal motility: studies using combined impedance-manometry. Clin Gastroenterol Hepatol 2004;2:230-236.

28. Tutuian R, Castell DO. Esophageal function testing: role of combined multichannel intraluminal impedance and manometry. Gastrointest Endosc Clin N Am 2005;15:265-275.

29. Zheng E, Gideon RM, Sloan J, Katz PO. Esophagogastric junction outflow obstruction is often associated with coexistent abnormal esophageal body motility and abnormal bolus transit. Dis Esophagus 2017;30:1-4.

30. Zizer E, Seufferlein T, Hänle MM. Impaired bolus clearance in combined high-resolution esophageal manometry and impedance measurement helps to differentiate between esophagogastric junction outflow obstruction and achalasia. Z Gastroenterol 2017;55:129-135. 